\title{
Notiz über Methylbrasilin
}

vort

\section{J. Herzig.}

Aus dem I. chemischen Laboratorium der k. k. Universität in Wien.

(Vorgelegt in der Sitzung am.5. Jänner 1893.)

Die Einwirkung von alkoholischem Kali auf die Alkylderivate einiger Körper der Quercetingruppe hat mir in Bezug auf die Ermittlung der Constitution derselben sehr gute Dienste geleistet, und ichwollte daher diese Reaction auch beim alkylirten Brasilin und Hämatoxylin anwenden. Ein Methylbrasilin war bereits von Schall und Dralle ${ }^{1}$ dargestellt worden, welchem sie die Formel eines Tetramethylbrasilins beilegten.

Bei der kritischen Durchsicht dieser interessanten Publication ist es mir aber aufgefallen, dass die Zahlen von Schall und Dralle eigentlich auf den Trimethyläther viel besser stimmen, und so musste ich die Arbeit mit dem analytischen Studium dieser Verbindung beginnen. Die Darstellung geschah nach den Angaben der genannten Autoren und habe ich denselben nichts hinzuzufügen. Ich erhielt den Äther in Form weisser glänzender Nadeln, deren constanter Schmelzpunkt bei $137-138^{\circ}$ lag.

Die Analyse dieser Verbindung ergab folgendes Resultat:

I. $0.2806 \mathrm{~g}$ bei $100^{\circ}$ getrockneter Substanz lieferte $0.7125 \mathrm{~g}$ Kohlensäure und $0.1540 \mathrm{~g}$ Wasser.

II. $0.2750 \mathrm{~g}$ bei $100^{\circ}$ getrockneter Substanz lieferte $0.6995 \mathrm{~g}$ Kohlensäure und $0 \cdot 1563 \mathrm{~g}$ Wasser.

In 100 Theilen

I. II.

$$
\begin{array}{lrr}
\text { C } \ldots \ldots .69 \cdot 25 & 69 \cdot 37 \\
\text { H ... . . } 6.09 & 6 \cdot 31
\end{array}
$$

1 Berl. Ber. XX, S. 3365, XXI, 3009, XXII, 1547. 
Wie aus folgender Zusammenstellung ersichtlich, stimmen diese Zahlen sowohl mit den Zahlen von Schall und Dralle als wie mit den theoretisch für Trimethylbrasilin geforderten so ziemlich überein.

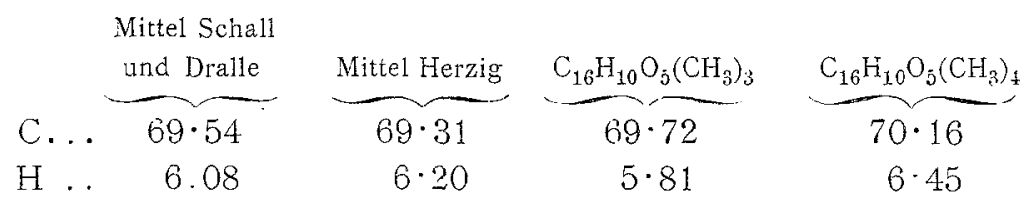

Dass hier in der That eine Trimethylverbindung vorliegt, beweisen bis zur Evidenz die Methoxylbestimmungen, welche folgendes Resultat lieferten.

I. $01870 \mathrm{~g}$ bei $100^{\circ}$ getrockneter Substanz gaben $0.4025 \mathrm{~g}$ Jodsilber.

II. $0.2235 \mathrm{~g}$ bei $100^{\circ}$ getrockneter Substanz gaben $0.4712 \mathrm{~g}$ Jodsilber.

In 100 Theilen

\begin{tabular}{|c|c|c|c|}
\hline I. & II. & $\mathrm{C}_{16} \mathrm{H}_{10} \mathrm{O}_{5}\left(\mathrm{CH}_{5}\right)$ & $\mathrm{C}_{16} \mathrm{H}_{10} \mathrm{O}_{5}\left(\mathrm{CH}_{3}\right)$ \\
\hline $\mathrm{CH}_{3} \mathrm{O} \ldots 28 \cdot 48$ & $27 \cdot 90$ & $28 \cdot 44$ & $36 \cdot 25$ \\
\hline
\end{tabular}

Ich habe mich für verpflichtet gefühlt, Herrn Dr. Schall dieses Resultat mitzutheilen, welcher inzwischen die Methoxylbestimmung bestätigen konnte. Trotzdem hält er die Existenz des Trimethyläthers nicht für bewiesen, weil er einen $Z$ weifel für berechtigt hält, ob unter diesen Umständen alles Methyl abgespalten wird. Einen derartigen Zweifel halte ich nach dem Stande unserer jetzigen Kenntnisse als ganz und gar unbegründet und ungerechtfertigt. Die Methoxylmethode hat seit ihrer Einführung durch $\mathrm{Ze}$ isel in ausserordentlich vielen Fällen Anwendung gefunden, und zwar immer mit ausgezeichnetem Erfolge. Es ist kein Fall bekannt, in welchem das Resultat dieser Methode mit den anderweitigen experimentellen Thatsachen im Widerspruch stünde. Ausserdem involvirt dieser Zweifel eine theilweise Negation aller mit Hilfe dieser Methode gefundenen interessanten Thatsachen, was doch wohl zu weit gehen würde. Ich halte daher die Existenz des Trimethyläthers für sicher festgestellt, und es handelt sich nur darum, welche Consequenzen sich für die Constitution des Brasilins daraus ergeben. 
Für die Anwesenheit von vier Hydroxylgruppen im Brasilin sprechen eine Reihe tetraacetylirter Derivate, welche dargestellt wurden. Man muss also in erster Linie an die von Graebe, ${ }^{1}$ Kostanecki $\mathrm{i}^{2}$ und mir $^{3}$ publicirten Beobachtungen denken, welche ergeben, dass bisweilen gewisse Hydroxylgruppen durch die Acetylirung nachgewiesen werden können, während die Alkylirung nicht mehr statt hat. Ich habe nun versucht, das Methylbrasilin noch weiter zu acetyliren, und muss bemerken, dass es mir bisher nicht gelungen ist, ein zur Analyse brauchbares Derivat $z$ u erhalter. Anderseits scheint aber, dass das Anhydrid doch auf den Äther einwirkt, aber das Studium dieser Reaction wird dadurch erschwert, dass das Methylbrasilin, wie schon Schall und Dralle bemerken, auch in einer amorphen Modification existirt. Trotz meines bisherigen Misserfolges halte ich desshalb doch die Existenz eines Monoacetyltrimethylbrasilins nicht für unmöglich. ${ }^{\bar{\gamma}}$

Sollte sich aber der Trimethyläther in keiner Weise acetyliren lassen, so wird dann ein erneuertes Studium sämmtlicher Tetraacetylderivate des Brasilins platzgreifen müssen.

Die Herren Schall und Dralle, deren Vorrecht in Bezug auf das Studium des Brasilins ich anerkennen muss, haben den Wunsch geäussert, diese Frage selbst weiter zu verfolgen, und ich will daher die Arbeit in diesem Stadium unterbrechen.

Ich behalte mir aber vor, die Einwirkung alkoholischen Kalis auf diesen Äther weiter zu studiren. Ebenso gedenke ich das Hämatoxylin, respective dessen Alkyläther in den Kreis meiner Studien zu ziehen.

1 Ann. Ch. Pharm., 209, S. 301.

2 Monatshefte für Chemie, XII, S. 320.

3 Monatshefte für Chemie, V, S. 72, IX, 548, XII, 161 und 177.

4 Berl. Ber. XXIII, S. 1430.

5 Versuche, die ich in den letzten Tagen gemacht habe, machen es wahrscheinlich, dass bei dieser Reaction doch ein Acetylmethylbrasilin entsteht. 